\title{
Functions and Mechanisms of Arginase in Age-Associated Cardiovascular Diseases
}

\author{
Xiu-Fen Ming • Zhihong Yang
}

Published online: 5 October 2013

(C) Springer Science+Business Media New York 2013

\begin{abstract}
Advanced age is a prominent risk factor of cardiovascular and metabolic diseases, such as atherosclerosis and type II diabetes. The underlying mechanisms are complex and not fully understood. Recent studies provide accumulating evidence demonstrating a potential role of arginases including arginase-I and arginase-II, the isoenzymes involved in L-arginine metabolism, in cardiovascular aging and metabolic diseases by affecting the functions of vascular endothelial cells, smooth muscle cells, and macrophages. At the molecular level, a positive interaction between the arginase II and mTOR-S6K1 pathway has been now demonstrated to play an important role in promoting oxidative stress, inflammation, cellular proliferation, senescence and death, which ultimately leads to accelerated vascular diseases and metabolic disorders. This article reviews the most recent advances in understanding the functional roles and mechanisms of arginase isoforms in cardiovascular aging and the potential of novel therapies to targeting arginases as a means to moderate cardiovascular and metabolic diseases associated with aging.
\end{abstract}

Keywords Advanced age $\cdot$ Hypertension - Atherosclerosis · Type II diabetes · Arginase · Oxidative stress · Inflammation · Cellular proliferation $\cdot$ Senescence $\cdot$ Isoforms $\cdot$ Cardiovascular disease $\cdot$ Metabolic disease

\section{Introduction}

Advanced age is highly associated with increased incidence and prevalence of cardiovascular and metabolic diseases including hypertension, atherosclerotic heart disease, stroke, obesity and

X.-F. Ming $(\varangle) \cdot$ Z. Yang

Vascular Biology, Department of Medicine, Division of Physiology,

Faculty of Science, University of Fribourg, Chemin du Musée 5,

1700 Fribourg, Switzerland

e-mail: xiu-fen.ming@unifr.ch obesity-related type II diabetes mellitus [1]. The prediction that advanced age population of our society will increase steadily in the future decades due to advancement of medical care system and therapeutic modalities raises an important challenging issue for our society [2], i.e., how to better moderate the high susceptibility of older adults to cardiovascular disease and metabolic disorders. Prior literature suggests that chronic low-grade inflammation and excessive oxidative stress are the key mechanisms linking cellular aging and age-associated diseases [3, 4]. However, it remains largely mysterious how inflammation and oxidative stress occur in aging and disease. In this article, we will briefly review the functional roles and molecular mechanisms of the enzyme arginase in promoting oxidative stress and inflammation that are involved in cellular aging and ageassociated cardiovascular and metabolic diseases.

\section{The Arginase Isoforms and Tissue/Cellular Distribution}

Arginase is a hydrolase that converts L-arginine to urea and Lornithine. Two major isoforms of arginase encoded by two different genes, i.e., cytoplasmic arginase-I (Arg-I) and mitochondrial arginase-II (Arg-II), have been identified [5]. The human Arg-I gene maps to chromosome 6q23 and encodes a 322 amino acid protein [6, 7], while the human Arg-II gene maps to chromosome 14q24.1 and encodes a 354 amino acid protein $[8,9]$. They show similar structure and share approximately $92 \%$ homology within the conserved regions while they share approximately $42 \%$ homology outside the conserved regions [8].

Arg-I and Arg-II are confined to distinct subcellular compartments and tissues. Arg-I is a cytosolic enzyme which is abundantly and constitutively expressed in liver [6] and also expressed at low levels in some of extrahepatic tissues including stomach, pancreas and lung [10॰]. Recent study demonstrates that it is also highly expressed in the red blood cells of 
humans and rodents [11]. Arg-II is a mitochondrial enzyme and abundantly expressed in kidney and widely expressed in extrahepatic tissues such as brain, prostate, intestine and pancreas $\left[8,10^{\bullet}\right]$ as well as in cells that are importantly involved in pathogenesis of cardiovascular diseases such as macrophages, vascular endothelial and smooth muscle cells $[12 \bullet$, $13 \cdot, 14 \bullet \cdot]$.

\section{Hepatic and Extrahepatic Functions of Arginase Isoforms}

Both isoforms of arginase hydrolyze L-arginine to urea and Lornithine [5]. In the liver, Arg-I is the sixth and final enzyme of the urea cycle responsible for elimination of excessive nitrogen generated primarily by the metabolism of amino acids derived from the food intake or from endogenous protein catabolism [15]. This function of Arg-I in the hepatic urea cycle is vital. Arg-I knockout mice exhibited severe symptoms of hyperammonemia, and died between postnatal days 10 and 14 [16]. Arg-I deficiency due to gene mutation in humans reveals hyperargininemia and exhibits neurologically based clinical symptoms in early childhood, including progressive neurologic impairment, development retardation, and hepatic dysfunction associated with cirrhosis and carcinoma $[15,17]$.

In extrahepatic tissues where there is no functioning urea cycle, both isoforms are believed to exert their functions through metabolizing L-arginine resulting in reduction of L-arginine and formation of L-ornithine with downstream production of polyamines and L-proline. By metabolizing L-arginine, arginases compete with nitric oxide synthase (NOS), including endothelial, inducible, and neuronal NOS (eNOS, iNOS and nNOS, respectively), for their common substrate L-arginine, leading to decreased NO production in endothelial cells, macrophages and in the neural tissue [18-20]. In addition, arginases also exert their biological effects through the downstream metabolites L-proline and polyamines. While L-proline is a precursor, along with vitamin $\mathrm{C}$, of collagen, polyamines are important for cell proliferation, anti-inflammatory effects in macrophages and neuroregeneration [18, 21, 22]. It has been hypothesized that an increased arginase gene expression and/or activity therefore play an important role in the pathogenesis of cardiovascular diseases through decreasing eNOS activity to produce NO as well as promoting smooth muscle cell proliferation and collagen production [18]. In supporting this notion, enhanced Arg-I in rats and Arg-II in mouse and humans have been shown to associate with decreased vasoprotective endothelial NO production linking to atherosclerosis, hypertension, diabetic endothelial dysfunction, diabetic nephropathy and age-associated cardiovascular dysfunction [23-27]. Moreover, a recent study reports that selective endothelial overexpression of Arg-II induces endothelial dysfunction and hypertension and enhances atherosclerosis in mice [28•]. Furthermore, inhibition of arginase pharmaceutically in rats and mice as well as genetic ablation of Arg-II in mice restores endothelial function in various disease conditions including atherosclerosis, hypertension and aging [23, 24, 26, 29].

Intriguingly, functions that are independent of L-arginine ureahydrolase activity for Arg-II in vascular smooth muscle cells have been recently shown to occur by our most recent study $[14 \bullet \cdot$, which will be discussed later in this review.

\section{Does Arginase Cause Endothelial Dysfunction Through L-arginine Deficiency?}

The hypothesis that increased arginase activity causes L-arginine deficiency leading to eNOS-uncoupling, a situation that eNOS produces $\mathrm{O}_{2}{ }^{-}$instead NO (Regarding detailed mechanisms of eNOS-uncoupling, please refer to the article [30]), vascular endothelial dysfunction is under ongoing debate. Though several groups demonstrated that supplementation of L-arginine improved endothelium-dependent vasodilation in disease animal models or patients with cardiovascular diseases [31, 32], numerous studies with supplemental L-arginine therapy either in animal models or humans do not show consistent results. No effect or no sustained effects on endothelial function [33-35], and even harmful effects on atherosclerotic lesion formation in Apolipoprotein $\mathrm{E}(\mathrm{ApoE}) / \mathrm{iNOS}$ double knockout mice have been reported with L-arginine supplementation [36]. Most importantly, a randomized, double-blinded, placebo-controlled study in patients with acute myocardial infarction, the VINTAGE MI study, demonstrates that 6-month oral L-arginine supplementation (3 g 3 times a day on top of standard postinfarction therapy) does not have any benefits on vascular stiffness and left ventricular ejection fraction, but increases mortality [37]. A second clinical trial in patients with peripheral artery disease, the so-called NO-PAIN study, shows decreased $\mathrm{NO}^{-}$production and shortened walking distance in patients receiving L-arginine supplementation as compared to the placebo group [38]. The impact of L-arginine supplementation, particularly chronic supplementation for treatment of cardiovascular diseases seems detrimental. These results have challenged the hypothesis whether L-arginine deficiency exists under disease conditions and whether arginase impairs endothelial function through depleting L-arginine bioavailability for endothelial NO production.

In fact, the concentration of L-arginine in adult human and mouse plasma is around $100 \mu \mathrm{mol} / \mathrm{L}$ and intracellular L-arginine concentration is between $50-200 \mu \mathrm{mol} / \mathrm{L}$, well above that required to support maximum eNOS activity $\left(\mathrm{K}_{\mathrm{m}}=2-20 \mu \mathrm{mol} / \mathrm{L}\right)$ [39]. A real L-arginine deficiency does not seem to occur. Yet, despite the sufficiently high intracellular concentrations of Larginine, increased extracellular L-arginine in cultured endothelial cells or acute L-arginine supplementation in patients and animals enhances NO production and endothelium-dependent relaxation, a phenomenon called "arginine paradox" [40]. Several hypotheses have been proposed to explain the "arginine paradox", which include the hypothesis of distinct intracellular 
L-arginine pools for NO production [41, 42]. In this hypothesis, one presumes that the exogenous L-arginine seems channeled to eNOS to produce $\mathrm{NO}$, while the intracellular L-arginine pool is not freely exchangeable with the extracellular L-arginine; however, it is accessible to both eNOS and arginase. This model could explain the "L-arginine paradox" and the observation that inhibition of arginase stimulates NO' production while overexpression of Arg-I or -II suppresses NO production in the endothelial cells, which is associated with only a mild reduction in intracellular L-arginine concentration (11 to $25 \%$ decrease) even in the presence of high extracellular concentration of L-arginine $(0.4 \mathrm{mmol} / \mathrm{L})$ [43].

The "distinct L-arginine pool" hypothesis has been however challenged by a recent study by Elms and colleagues [44••]. In this study, the investigators show that inhibition of eNOS activity by Arg-I cannot be modified by targeting eNOS or Arg-I to disparate intracellular compartments in the presence of L-arginine supplementation. A different explanation for the "arginine paradox" is the "ADMA hypothesis". ADMA is the endogenous eNOS inhibitor, which blocks intracellular Larginine utility by eNOS to produce NO [45]. It is assumed that an increase in arginase activity in the presence of ADMA in endothelial cells would further significantly limit intracellular L-arginine bioavailability for eNOS to produce NO, although the intracellular L-arginine concentration is only mildly decreased. Whether L-arginine supplementation under the condition of "relative L-arginine deficiency" causes detrimental effects due to production of other undesired metabolites from L-arginine via arginase such as urea and L-ornithine which is further metabolized to polyamines, is not fully clear $[18,21,22]$. Results available from the literature do not seem to support this hypothesis. One study reports that polyamines stimulate autophagy process preventing cellular aging [46]. Moreover, urea and L-ornithine do not show any effects on eNOS activity [44*0]. There is also no linear relationship between arginase activity and eNOS inhibition [44••], suggesting that the inhibitory effect of arginase on eNOS activity is not entirely due to L-arginine depletion. Consistent with these findings, our most recently published study demonstrates that Arg-II exhibits detrimental vascular effects in atherosclerosis also through some of its L-arginine ureahydrolase activity-independent mechanisms [14••].

\section{L-arginine Ureahydrolase Activity Independent Effects of Arginase}

Since enzymes may have pleiotropic or off-target effects, we would like to address the question whether Arg-II exhibits its biological functions only through its L-arginine metabolizing effect or through regulation of the L-arginine/NO pathway. For this purpose, we have recently generated a catalytically inactive Arg-II mutant with a point mutation of histidine to phenylalanine at position 160 , referred to as $\mathrm{H} 160 \mathrm{~F}$, and investigated the functions of this mutant in the vascular smooth muscle cells (VSMC) that do not produce NO $[13 \bullet, 14 \bullet \cdot]$. We found that in VSMC, the long term overexpressing wild type Arg-II gene as well as the enzymatically inactive H160F mutant, promote VSMC apoptosis and senescence, whereas only the wild type Arg-II (not the H160F inactive mutant) is able to enhance the cell proliferation $[13 \bullet, 14 \cdot \bullet]$. This intriguing result demonstrates that Arg-II on the one hand promotes VSMC proliferation and on the other hand causes VSMC apoptosis and senescence. While the cell proliferation-stimulating effect of Arg-II is dependent on its L-arginine ureahydrolase activity via synthesis of ornithine and polyamines as shown by previous reports [22], the cell apoptosis/ senescence-promoting effect is independent of its enzymatic activity. Further experiments show that this L-arginine ureahydrolase activity-independent effect is mediated through the protein kinases $\mathrm{S} 6 \mathrm{~K} 1$ and ERK1/2, that in turn activate p66Shc leading to $\mathrm{H}_{2} \mathrm{O}_{2}$ production and mitochondrial dysfunction, cellular apoptosis and senescence $[13 \bullet, 14 \bullet \cdot]$. In parallel to these signaling pathways, p53 is also activated by Arg-II independently of its L-arginine ureahydrolase activity, contributing to the cell senescence of the apoptosis process [13•, 14••]. Importantly, expression of Arg-II and activities of S6K1, ERK1/2, p66Shc, and p53 are all augmented in senescent VSMC, and genetic inhibition or ablation of Arg-II not only reduces these signaling pathways and VSMC senescence/apoptosis in vitro, but also in atherosclerosis-prone $\mathrm{ApoE}^{-/-}$mice in vivo, which at least in part accounts for the reduced plaque lesion formation and a more stable plaque characteristics in aortic roots in Arg-IIdeficient $\mathrm{ApoE}^{-/-}$mice $[13 \bullet, 14 \bullet \bullet]$. Moreover, our recent studies provide evidence that Arg-II promotes vascular dysfunction and atherosclerosis also through activation of macrophage inflammation, an effect that seems unlikely mediated by its L-arginine metabolizing mechanism (unpublished data) [12••]. How Arg-II, independently of its L-arginine ureahydrolase activity, promotes VSMC senescence/apoptosis requires further investigation. Whether these enzymatic dependent and independent effects also exist for Arg-I awaits investigation.

\section{Mechanisms of Regulation of Arginase Expression and Activity}

While Arg-I is the isoform expressed in the liver across different species including rodents and humans, the isoforms expressed in the cardiovascular tissues/cells seem to exhibit some species-specific differences. Although vascular endothelial and smooth muscle cells express both Arg-I and Arg-II, the relative level of the two isozymes seems different depending on species [18]. In human and mouse vasculature, Arg-II seems to be the predominant isoenzyme [23,47], whereas in rats and pigs, Arg-I seems to play an important role in regulation of vascular functions [29]. Arg-II expression/activity in the 
vascular cells are usually very low; it is, however, significantly induced under several physiological, particularly in pathological conditions, including aging, atherosclerosis, and diabetes mellitus [13•, 23, 24, 26, 27].

Several signal transduction pathways have been explored being involved in the regulation of expression and activity of arginases. In macrophages, up-regulation of Arg-I is associated with M2 anti-inflammatory phenotype [48], which is mediated by cAMP, IL-4 and TGF- $\beta$ [49]. In the vascular cells including endothelial cells and smooth muscle cells, IL-13 is reported to upregulate both Arg-I and Arg-II in the lung causing pulmonary arteriole remodeling and subsequently pulmonary hypertension in mouse [50]. In human pulmonary arterial smooth muscle cells, hypoxia is capable of inducing Arg-II expression through cAMP [51]. However, another study shows that cAMP, besides JAK/STAT6 upregulates Arg-I (not Arg-II) in rat aortic smooth muscle cells upon stimulation by IL-4 or IL13 [52]. It is not clear whether this could be explained by the different biological properties of smooth muscle cells of different origins or species or the different stimuli used in their experimental settings.

Other important regulatory signals for arginases are the small G-protein RhoA and its downstream kinase ROCK [23, 53], p38mapk [54] as well as S6K1 as demonstrated by our most recent studies [13•, 14••]. There is emerging evidence suggesting that oxidative stress, hyperglycaemia, and aging may upregulate arginase activity and expression through these signaling pathways [55-59]. Our recent study demonstrates a positive cross talk between S6K1 and Arg-II in endothelial cells, which is importantly involved in vascular endothelial aging, endothelial-monocyte interaction due to enhanced endothelial expression of adhesion molecules VCAM-1 and ICAM-
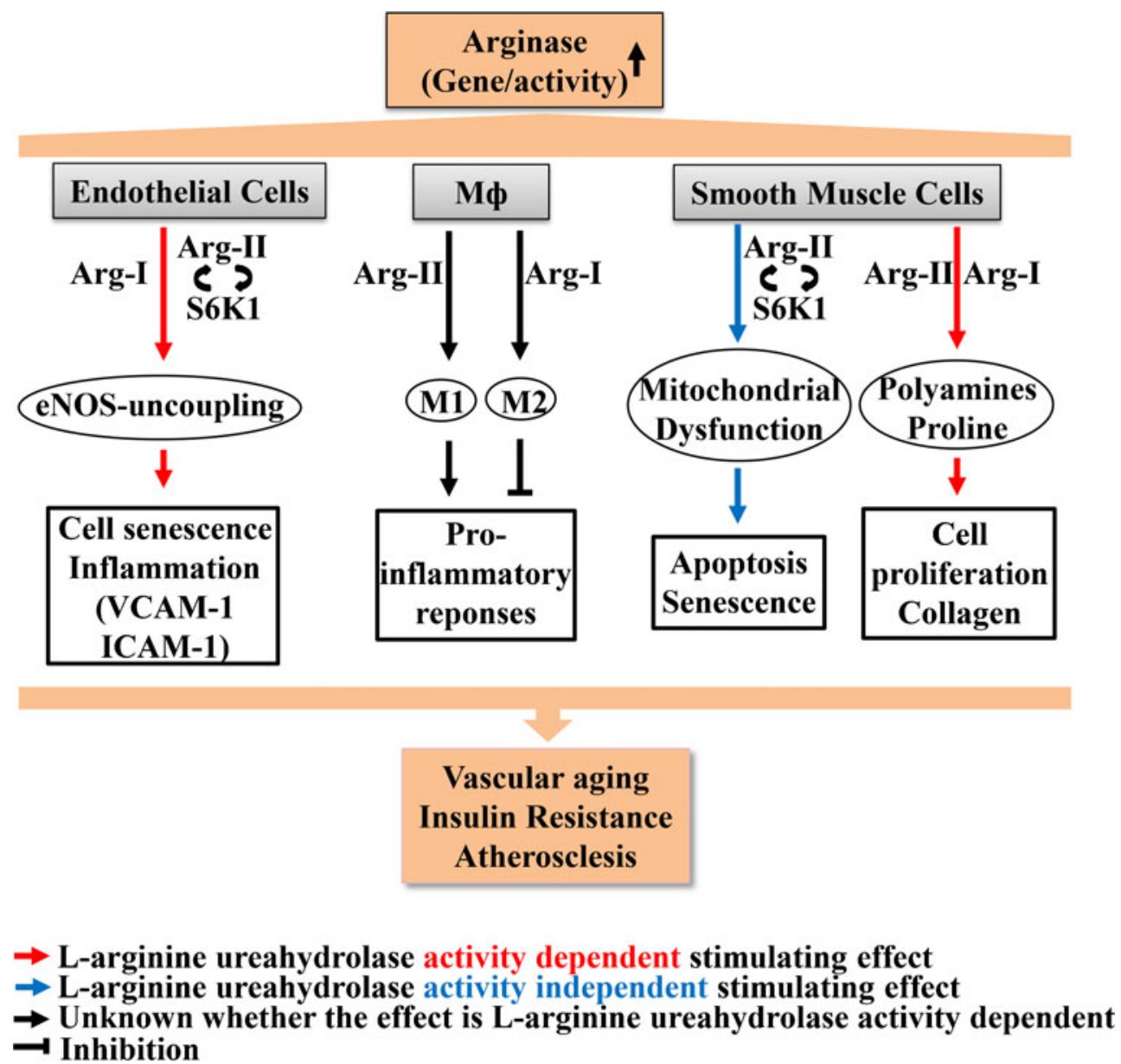

Fig. 1 Summary of the multiple roles of arginases in age-associated cardiovascular diseases. 1) In endothelial cells, enhanced expression/ activity of Arg-I or Arg-II that positively cross talks with S6K1 causes eNOS-uncoupling, leading to endothelial senescence and inflammation. 2) In macrophages, enhanced Arg-I is associated with anti-inflammatory M2 phenotype, whereas enhanced Arg-II has been shown to promote macrophage pro-inflammatory responses through mitochondrial ROS. 3) In VSMC, enhanced Arg-I or Arg-II activity promotes cell proliferation and collagen production through their downstream metabolites derived from L-arginine, polyamine and L-proline, respectively. On the other hand, enhanced Arg-II gene expression, which positively cross talks with S6K1, induces mitochondrial dysfunction leading to cell senescence and apoptosis independently of its L-arginine ureahydrolase activity. All the effects exerted by arginases promote cardiovascular aging, insulin resistance and atherosclerosis. The meaning of the colors of the arrow is indicated in the figure 
1 through uncoupling of eNOS. Moreover, our most recent study also demonstrates a positive cross talk among ERK1/2S6K1-p66Shc and Arg-II in VSMC [14••].

\section{Conclusion/Perspectives}

Increasing evidence demonstrates the potential role of arginase, particularly Arg-II as a therapeutic target in cardiovascular diseases associated with aging such as atherosclerosis and type-II diabetes. A deficiency of Arg-II reduces macrophage inflammatory responses, vascular inflammation and oxidative stress, and VSMC apoptosis in mice fed high cholesterol diet and high fat diet, and improves endothelial function in aging, reduces atherosclerosis and improves insulin sensitivity and

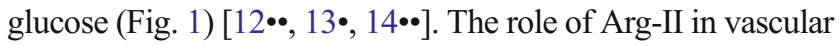
diseases is further confirmed by a study showing that endothelial specific Arg-II transgenic mice on $\mathrm{ApoE}^{-/-}$background reveal accelerated atherosclerosis [28 $8^{\bullet}$. Although some studies implicate that targeting Arg-I is also of therapeutic relevance in cardiovascular diseases, firm evidence is still lacking, which is due to the fact that systemic Arg-I deficient mouse died between postnatal days 10 and 14 [16], and an endothelial specific Arg-I knockout mouse is not yet available.

The therapeutic potential of targeting arginases with inhibitors has been demonstrated in a number of experimental models of cardiovascular disease with the improved endothelial function as a primary end point. This has been demonstrated for a range of human studies, including elderly [60], hypertensive [61], and coronary artery disease and type 2 diabetic [62] populations. While it remains of concern that these inhibitors could theoretically inhibit liver Arg-I and lead to hyperammonemia, this side effect has not been reported. All the studies are solely dependent on the pharmacological inhibitors which inhibit both isoforms of arginases. Development of isoform-specific arginase inhibitors is desirable.

Since Arg-II exhibits a L-arginine ureahydrolase activity independent effect, inhibitors that only target its enzymatic activity may not fully achieve our goals of treatment of cardiovascular disease. Pharmacological drugs that are capable of reducing the Arg-II protein level in aging and age-associated diseases such as atherosclerosis and diabetes would be more efficient and desirable. Pharmacological agents that target signaling transduction pathways regulating arginase gene expression such as rapamycin or resveratrol that inhibit the mTOR/ S6K1 pathway involved in upregulation of Arg-II levels recouples eNOS function in aging animal models [13•, 63], and also inhibit smooth muscle cell apoptosis and senescence [14*0]. One of the major challenges of further research is to understand the regulatory mechanisms of gene expression of arginase including Arg-I and Arg-II in different cells and under different physiological and pathological conditions, which will allow development of strategies that specifically target isoforms of the enzyme in specific tissues or cells.

Acknowledgments The original studies from the authors' own research were supported by the Swiss National Science Foundation $(310000-120435 / 1$ and $310030141070 / 1)$ and the Swiss Heart Foundation.

\section{Compliance with Ethics Guidelines}

Conflict of Interest Xiu-Fen Ming and Zhihong Yang declare that they have no conflict of interest.

Human and Animal Rights and Informed Consent This article does not contain any studies with human or animal subjects performed by any of the authors.

\section{References}

Papers of particular interest, published recently, have been highlighted as:

- Of importance

-• Of major importance

1. Fontana L. Modulating human aging and age-associated diseases. Biochim Biophys Acta. 2009;1790:1133-8.

2. Sidney S, Rosamond WD, Howard VJ, Luepker RV. The "heart disease and stroke statistics-2013 update" and the need for a national cardiovascular surveillance system. Circulation. 2013;127:21-3.

3. Lonn ME, Dennis JM, Stocker R. Actions of "antioxidants" in the protection against atherosclerosis. Free Radic Biol Med. 2012;53: 863-84

4. Hansson GK, Hermansson A. The immune system in atherosclerosis. Nat Immunol. 2011;12:204-12.

5. Jenkinson CP, Grody WW, Cederbaum SD. Comparative properties of arginases. Comp Biochem Physiol B Biochem Mol Biol. 1996;114: 107-32.

6. Dizikes GJ, Grody WW, Kern RM, Cederbaum SD. Isolation of human liver arginase cDNA and demonstration of nonhomology between the two human arginase genes. Biochem Biophys Res Commun. 1986;141:53-9.

7. Sparkes RS, Dizikes GJ, Klisak I, Grody WW, Mohandas T, Heinzmann $\mathrm{C}$, et al. The gene for human liver arginase (ARG1) is assigned to chromosome band 6q23. Am J Hum Genet. 1986;39:186-93.

8. Vockley JG, Jenkinson CP, Shukla H, Kern RM, Grody WW, Cederbaum SD. Cloning and characterization of the human type II arginase gene. Genomics. 1996;38:118-23.

9. Gotoh T, Araki M, Mori M. Chromosomal localization of the human arginase II gene and tissue distribution of its mRNA. Biochem Biophys Res Commun. 1997;233:487-91.

10. • Choi S, Park C, Ahn M, Lee JH, Shin T. Immunohistochemical study of arginase 1 and 2 in various tissues of rats. Acta Histochem. 2012;114:487-94. An important study demonstrating the expression pattern of Arg-I and Arg-II in various tissues by both immunoblotting and immunohistochemistry.

11. Yang J, Gonon AT, Sjoquist PO, Lundberg JO, Pernow J. Arginase regulates red blood cell nitric oxide synthase and export of cardioprotective nitric oxide bioactivity. Proc Natl Acad Sci U S A. 2013. doi:10.1073/pnas.1307058110. 
12. • Ming XF, Rajapakse AG, Yepuri G, Xiong Y, Carvas JM, Ruffieux J, et al. Arginase II promotes macrophage inflammatory responses through mitochondrial reactive oxygen species, contributing to insulin resistance and atherogenesis. J Am Heart Assoc. 2012;1:e00992. This is the first study showing that Arg-II, in contrast to Arg-I that is associated with anti-inflammmatory M2 macrophage phenotype, promotes M1 macrophage pro-inflammatory responses through mitochondrial reactive oxigen stress contributing to insulin resistance and atherosclerosis.

13. - Yepuri G, Velagapudi S, Xiong Y, Rajapakse AG, Montani JP, Ming $\mathrm{XF}$, et al. Positive crosstalk between arginase-II and S6K1 in vascular endothelial inflammation and aging. Aging Cell. 2012;11:1005-16. This study reveals a novel mechanism of mutual positive cross talk beween Arg-II and S6K1 in vascular endothelial inflammation and aging.

14. •• Xiong Y, Yu Y, Montani JP, Yang Z, Ming XF. Arginase-II induces vascular smooth muscle cell senescence and apoptosis through p66Shc and p53 independently of its 1-Arginine ureahydrolase activity: implications for atherosclerotic plaque vulnerability. J Am Heart Assoc. 2013;2:e000066. This study for the first time uncovers a novel mechanism of Arg-II, independently of its L-arginine ureahydrolase activity, in promoting mitochondrial dysfunction leading to VSMC senescence and apoptosis that ultimately contribute to atherosclerotic plaque instability. This finding is important for the drug development targeting Arg-II, which should also take its enzyme activityindependent effects into account.

15. Crombez EA, Cederbaum SD. Hyperargininemia due to liver arginase deficiency. Mol Genet Metab. 2005;84:243-51.

16. Iyer RK, Yoo PK, Kern RM, Rozengurt N, Tsoa R, O'Brien WE, et al. Mouse model for human arginase deficiency. Mol Cell Biol. 2002;22: 4491-8.

17. Tsang JP, Poon WL, Luk HM, Fung CW, Ching CK, Mak CM, et al. Arginase deficiency with new phenotype and a novel mutation: contemporary summary. Pediatr Neurol. 2012;47:263-9.

18. Yang Z, Ming XF. Endothelial arginase: a new target in atherosclerosis. Curr Hypertens Rep. 2006;8:54-9.

19. Stempin CC, Dulgerian LR, Garrido VV, Cerban FM. Arginase in parasitic infections: macrophage activation, immunosuppression, and intracellular signals. J Biomed Biotechnol. 2010;2010:683485.

20. Lange PS, Langley B, Lu P, Ratan RR. Novel roles for arginase in cell survival, regeneration, and translation in the central nervous system. J Nutr. 2004;134:2812S-7S.

21. Wei LH, Wu G, Morris Jr SM, Ignarro LJ. Elevated arginase I expression in rat aortic smooth muscle cells increases cell proliferation. Proc Natl Acad Sci U S A. 2001;98:9260-4.

22. Durante W, Liao L, Reyna SV, Peyton KJ, Schafer AI. Transforming growth factor-beta(1) stimulates L-arginine transport and metabolism in vascular smooth muscle cells: role in polyamine and collagen synthesis. Circulation. 2001;103:1121-7.

23. Ming XF, Barandier C, Viswambharan H, Kwak BR, Mach F, Mazzolai L, et al. Thrombin stimulates human endothelial arginase enzymatic activity via RhoA/ROCK pathway: implications for atherosclerotic endothelial dysfunction. Circulation. 2004;110:3708-14.

24. Demougeot C, Prigent-Tessier A, Marie C, Berthelot A. Arginase inhibition reduces endothelial dysfunction and blood pressure rising in spontaneously hypertensive rats. J Hypertens. 2005;23:971-8.

25. Kim JH, Bugaj LJ, Oh YJ, Bivalacqua TJ, Ryoo S, Soucy KG, et al. Arginase inhibition restores NOS coupling and reverses endothelial dysfunction and vascular stiffness in old rats. J Appl Physiol. 2009;107:1249-57.

26. Ryoo S, Gupta G, Benjo A, Lim HK, Camara A, Sikka G, et al. Endothelial arginase II: a novel target for the treatment of atherosclerosis. Circ Res. 2008;102:923-32.

27. You H. Arginase inhibition mediates renal tissue protection in diabetic nephropathy by a nitric oxide synthase 3-dependent mechanism. Kidney Int. 2013. doi:10.1038/ki.2013.215.

28. • Vaisman BL, Andrews KL, Khong SM, Wood KC, Moore XL, Fu Y, et al. Selective endothelial overexpression of arginase II induces endothelial dysfunction and hypertension and enhances atherosclerosis in mice. PLoS One. 2012;7:e39487. This is the first study evaluating the effect of endothelial-specific elevation of arginase II expression on endothelial function and the development of atherosclerosis. The study demonstrates that overexpression of arginase II in the endothelium in vivo is detrimental to the cardiovascular system.

29. White AR, Ryoo S, Li D, Champion HC, Steppan J, Wang D, et al. Knockdown of arginase I restores NO signaling in the vasculature of old rats. Hypertension. 2006;47:245-51.

30. Yang Z, Ming XF. Arginase: the emerging therapeutic target for vascular oxidative stress and inflammation. Front Immunol. 2013;4:149.

31. Girerd XJ, Hirsch AT, Cooke JP, Dzau VJ, Creager MA. L-arginine augments endothelium-dependent vasodilation in cholesterol-fed rabbits. Circ Res. 1990;67:1301-8.

32. Creager MA, Gallagher SJ, Girerd XJ, Coleman SM, Dzau VJ, Cooke JP. L-arginine improves endothelium-dependent vasodilation in hypercholesterolemic humans. J Clin Invest. 1992;90:1248-53.

33. Loscalzo J. Adverse effects of supplemental L-arginine in atherosclerosis: consequences of methylation stress in a complex catabolism? Arterioscler Thromb Vasc Biol. 2003;23:3-5.

34. Oomen CM, van Erk MJ, Feskens EJ, Kok FJ, Kromhout D. Arginine intake and risk of coronary heart disease mortality in elderly men. Arterioscler Thromb Vasc Biol. 2000;20:2134-9.

35. Wennmalm A, Edlund A, Granstrom EF, Wiklund O. Acute supplementation with the nitric oxide precursor L-arginine does not improve cardiovascular performance in patients with hypercholesterolemia. Atherosclerosis. 1995; 118:223-31.

36. Chen J, Kuhlencordt P, Urano F, Ichinose H, Astern J, Huang PL. Effects of chronic treatment with L-arginine on atherosclerosis in apoE knockout and apoE/inducible NO synthase double-knockout mice. Arterioscler Thromb Vasc Biol. 2003;23:97-103.

37. Schulman SP, Becker LC, Kass DA, Champion HC, Terrin ML, Forman S, et al. L-arginine therapy in acute myocardial infarction: the Vascular Interaction With Age in Myocardial Infarction (VINTAGE MI) randomized clinical trial. JAMA. 2006;295:58-64.

38. Wilson AM, Harada R, Nair N, Balasubramanian N, Cooke JP. Larginine supplementation in peripheral arterial disease: no benefit and possible harm. Circulation. 2007;116:188-95.

39. Morris Jr SM. Regulation of enzymes of the urea cycle and arginine metabolism. Annu Rev Nutr. 2002;22:87-105.

40. Kurz S, Harrison DG. Insulin and the arginine paradox. J Clin Invest. 1997;99:369-70.

41. Topal G, Brunet A, Walch L, Boucher JL, David-Dufilho M. Mitochondrial arginase II modulates nitric-oxide synthesis through nonfreely exchangeable L-arginine pools in human endothelial cells. J Pharmacol Exp Ther. 2006;318:1368-74.

42. Santhanam L, Christianson DW, Nyhan D, Berkowitz DE. Arginase and vascular aging. J Appl Physiol. 2008;105:1632-42.

43. Li H, Meininger CJ, Hawker Jr JR, Haynes TE, Kepka-Lenhart D, Mistry SK, et al. Regulatory role of arginase I and II in nitric oxide, polyamine, and proline syntheses in endothelial cells. Am J Physiol Endocrinol Metab. 2001;280:E75-82.

44. •• Elms S, Chen F, Wang Y, Qian J, Askari B, Yu Y, et al. Insights into the arginine paradox: evidence against the importance of subcellular location of arginase and eNOS. Am J Physiol Heart Circ Physiol. 2013;305:H651-66. This study provides evidence agaist the hypothesis of distinct intracellular L-arginine pools for the "arginine paradox".

45. Antoniades C, Shirodaria C, Leeson P, Antonopoulos A, Warrick N, VanAssche T, et al. Association of plasma asymmetrical dimethylarginine (ADMA) with elevated vascular superoxide production and endothelial nitric oxide synthase uncoupling: implications for endothelial function in human atherosclerosis. Eur Heart J. 2009;30:1142-50.

46. Eisenberg T, Knauer H, Schauer A, Buttner S, Ruckenstuhl C, Carmona-Gutierrez D, et al. Induction of autophagy by spermidine promotes longevity. Nat Cell Biol. 2009;11:1305-14. 
47. Bachetti T, Comini L, Francolini G, Bastianon D, Valetti B, Cadei M, et al. Arginase pathway in human endothelial cells in pathophysiological conditions. J Mol Cell Cardiol. 2004;37:515-23.

48. Munder M, Eichmann K, Moran JM, Centeno F, Soler G, Modolell M. Th1/Th2-regulated expression of arginase isoforms in murine macrophages and dendritic cells. J Immunol. 1999;163:3771-7.

49. Morris Jr SM. Regulation of arginine availability and its impact on NO synthesis. In: Ignarro LJ, editor. Nitric oxide. Biology and pathobiology. San Diego: Academic Press; 2000. p. 187-97.

50. Cho WK, Lee CM, Kang MJ, Huang Y, Giordano FJ, Lee PJ, et al. IL-13 receptor alpha2-arginase 2 pathway mediates IL-13-induced pulmonary hypertension. Am J Physiol Lung Cell Mol Physiol. 2013;304:L112-24.

51. Chen B, Calvert AE, Meng X, Nelin LD. Pharmacologic agents elevating cAMP prevent arginase II expression and proliferation of pulmonary artery smooth muscle cells. Am J Respir Cell Mol Biol. 2012;47:218-26.

52. Wei LH, Jacobs AT, Morris Jr SM, Ignarro LJ. IL-4 and IL-13 upregulate arginase I expression by cAMP and JAK/STAT6 pathways in vascular smooth muscle cells. Am J Physiol Cell Physiol. 2000;279:C248-56.

53. Ryoo S, Bhunia A, Chang F, Shoukas A, Berkowitz DE, Romer LH. OxLDL-dependent activation of arginase II is dependent on the LOX-1 receptor and downstream RhoA signaling. Atherosclerosis. 2011;214:279-87.

54. Denise ME, De Nicola GF, Marber MS. New therapeutic targets in cardiology: p38 alpha mitogen-activated protein kinase for ischemic heart disease. Circulation. 2012;126:357-68.

55. Toque HA, Romero MJ, Tostes RC, Shatanawi A, Chandra S, Carneiro ZN, et al. p38 Mitogen-activated protein kinase (MAPK) increases arginase activity and contributes to endothelial dysfunction in corpora cavernosa from angiotensin-II-treated mice. J Sex Med. 2010;7:3857-67.

56. Toque HA, Nunes KP, Yao L, Liao JK, Webb RC, Caldwell RB, et al. Activated rho kinase mediates diabetes-induced elevation of vascular arginase activation and contributes to impaired corpora cavernosa relaxation: possible involvement of p38 MAPK activation. J Sex Med. 2013;10:1502-15.

57. Thengchaisri N, Hein TW, Wang W, Xu X, Li Z, Fossum TW, et al. Upregulation of arginase by $\mathrm{H} 2 \mathrm{O} 2$ impairs endothelium-dependent nitric oxide-mediated dilation of coronary arterioles. Arterioscler Thromb Vasc Biol. 2006;26:2035-42.

58. Sankaralingam S, Xu H, Davidge ST. Arginase contributes to endothelial cell oxidative stress in response to plasma from women with preeclampsia. Cardiovasc Res. 2010;85:194-203.

59. Romero MJ, Platt DH, Tawfik HE, Labazi M, El-Remessy AB, Bartoli M, et al. Diabetes-induced coronary vascular dysfunction involves increased arginase activity. Circ Res. 2008;102:95-102.

60. Holowatz LA, Santhanam L, Webb A, Berkowitz DE, Kenney WL. Oral atorvastatin therapy restores cutaneous microvascular function by decreasing arginase activity in hypercholesterolaemic humans. J Physiol. 2011;589:2093-103.

61. Holowatz LA, Kenney WL. Up-regulation of arginase activity contributes to attenuated reflex cutaneous vasodilatation in hypertensive humans. J Physiol. 2007;581:863-72.

62. Shemyakin A, Kovamees O, Rafnsson A, Bohm F, Svenarud P, Settergren $\mathrm{M}$, et al. Arginase inhibition improves endothelial function in patients with coronary artery disease and type 2 diabetes mellitus. Circulation. 2012;126:2943-50.

63. Rajapakse AG, Yepuri G, Carvas JM, Stein S, Matter CM, Scerri I, et al. Hyperactive S6K1 mediates oxidative stress and endothelial dysfunction in aging: inhibition by resveratrol. PLoS One. 2011;6:e19237. 